Petrovska K, Watts NP, Catling C, Bisits A, Homer CS. 'Stress, anger, fear and injustice': An international qualitative survey of women's experiences planning a vaginal breech birth. Midwifery 44:41-47 21 Nov 2016 (in press). DOI: http://dx.doi.org/10.1016/j.midw.2016.11.005

\title{
"Stress, anger, fear and injustice": An international qualitative survey of women's experiences planning a vaginal breech birth
}

\section{ABSTRACT}

\section{Objective:}

The outcomes of the Term Breech Trial had a profound impact on women's options for breech birth, with caesarean section now seen as the default method for managing breech birth by many clinicians. Despite this, the demand for planned vaginal breech birth from women does exist. This study aimed to examine the experiences of women who sought a vaginal breech birth to increase understanding as to how to care for women seeking this birth option.

\section{Design:}

An electronic survey was distributed to women online via social media. The survey consisted of qualitative and quantitative questions, with the qualitative data being the focus of this paper. Open ended questions sought information on the ways in which woman sourced a clinician skilled in vaginal breech birth and the level of support and quality of information provided from clinicians regarding vaginal breech birth. Thematic analysis was used to analyse and code the qualitative data into major themes.

\section{Findings:}

In total, 204 women from over seven countries responded to the survey. Written responses to the open ended questions were categorised into seven themes: Seeking the chance to try for a VBB; Encountering 
coercion and fear; Putting the birth before the baby?; Dealing with emotional wounds; Searching for information and support; Traveling across boundaries; Overcoming obstacles in the system.

\section{Key Conclusions:}

For women seeking vaginal breech birth, limited system and clinical support can impede access to balanced information and options for care. Recognition of existing evidence on the safety of vaginal breech birth, as well as the presence of clinical guidelines that support it, may assist in promoting vaginal breech birth as a legitimate option that should be available to women.

Keywords: Vaginal breech birth, support, decision-making, women's experiences 


\section{Introduction}

The outcomes of the Term Breech Trial had a profound impact on women's choices for birth of their breech presenting baby, with the findings of the Trial concluding that caesarean section (CS) was the safest mode of birth for babies in the breech position (Glezerman 2006; Hannah et al. 2000; Kotaska et al. 2009; Lawson 2012). The swift response from maternity facilities across the world was to virtually abandon planned vaginal breech birth (VBB) in favour of elective CS for management of breech presentation at term (Berhan \& Haileamlak 2016). The design and recommendations of the Term Breech Trial have since been the subject of significant critique (Catling et al. 2016; Glezerman 2006, 2012; Lawson 2012). Additionally, subsequent research has also shown that vaginal breech birth can be a safe option for carefully selected women with the appropriate care and expertise (Borbolla Foster et al. 2014; Glezerman 2012; Goffinet et al. 2006; Kotaska et al. 2009; Lawson 2012).

For the $3-5 \%$ of women who have a breech presentation at the end of their pregnancy, the options for birth in many high income countries have largely diminished with CS now seen by many facilities as the default method for managing breech birth (Borbolla Foster et al. 2014; Guittier et al. 2011; Kotaska et al. 2009). This has contributed to the rise in CS (and its associated morbidity), a lack of support for women who may seek a VBB, and a lack of clinicians who have the skills to provide that care (Berhan \& Haileamlak 2016; Catling et al. 2016; Homer et al. 2015; Petrovska et al. 2016; Walker, Scamell \& Parker 2016).

Clinician skill in supporting VBB, once an integral part of obstetric and midwifery training, virtually disappeared, with the number of clinicians skilled in facilitating VBBs decreasing to almost non-existent levels in many institutions (Borbolla Foster et al. 2014; Glezerman 2012; Lawson 2012; Walker, Scamell \& Parker 2016). Recent research has suggested that in order to address the shortage of skilled clinicians, structured training programs may contribute to increasing professional competence and confidence in physiological VBB as a normal practice (Walker, Scamell \& Parker 2016). These programs may facilitate 
maternity services to address the lack of options many women currently face when seeking the opportunity to birth their breech baby vaginally. Without the availability of skilled clinicians, women considering planned VBB face numerous obstacles in seeking information for this birth option as facilities that support VBB continue to be largely unavailable (Catling et al. 2016; Glezerman 2012; Hogle et al. 2003; Homer et al. 2015; Kotaska et al. 2009; Phipps et al. 2003).

Few studies exist on the experience of women who are seeking information to assist them in their decision-making for VBB. The limited research that does exist suggests that accessing support for vaginal breech birth can be challenging for women seeking this option for birth (Guittier et al. 2011; Homer et al. 2015). Given a demand for VBB does exist, and there is continuing support in the literature about the need to increase the availability of this option for birth, it is important to examine the experiences of women to increase understanding as to how care for planned VBB can be optimised (Glezerman 2012; Kotaska et al. 2009; Lawson 2012; van Roosmalen \& Meguid 2014). Little is known about the global experiences of women from high income countries and the similarities and differences in their experiences in seeking the option of VBB. Therefore, the aim of this study was to examine the views and experiences of women from a number of high income countries who sought a VBB, with a view to increase understanding as to how these women can be best supported should they choose this option for care.

\section{Methods}

An electronic survey was developed by the research team for distribution to women online via social media. The aim of the survey was to gather data on women's expectations and experiences surrounding planned VBB. The survey was targeted at women who have planned a vaginal breech birth at or close to full term in the past 7 years, regardless of whether the final outcome was a vaginal breech birth or a caesarean section. The survey was designed to gather both qualitative and quantitative data. Data from the open ended questions included in the survey were analysed for this paper. The open ended 
questions focused on the methods used by the woman to source a clinician skilled in VBB; use of the internet to source information on vaginal breech birth; the level of support from family and friends; and the level of support and quality of information provided from clinicians regarding VBB. Survey questions were developed and informed by the data gathering methods used in previous qualitative research that involved semi- structured interviews with women who planned a VBB (Homer et al. 2015). The survey was piloted with two women who had planned a VBB; one had a VBB, the other a CS in labour. Following feedback, the survey was modified to ensure survey questions were accessible and unambiguous.

\section{Data Collection}

Previous research shows that women access social media to gather information and interact with other women who have had or are planning a VBB (Homer et al. 2015). This method of information gathering is frequently used by pregnant women for decision-making about birth (Dahlen \& Homer 2011; Lagan, Sinclair \& Kernohan 2011; Munro, Kornelsen \& Hutton 2009; Romano, Gerber \& Andrews 2010). It was therefore decided to use social media to distribute this survey. In order to facilitate sharing of the survey, it was first uploaded onto SurveyMonkey ${ }^{\circledR}$, an online platform that allows the distribution of research surveys for a nominal fee. Once uploaded, a link to the survey was distributed via closed membership Facebook groups from the United States, United Kingdom and Australia that had a focus on VBB and whose membership to these groups is not limited to women from each of these countries. Ethical approval for distribution of the survey was granted by both the Local Health District and the University's Human Research Ethics Committee.

The survey was posted from April 2014 to January 2015. This extended period of data collection was implemented to maximise the sample size of respondents, given planned vaginal breech birth is a relatively rare occurrence. During this period, one researcher was responsible for providing two reminders to ensure as many women as possible viewed the link to the survey. Women who were 
involved in previous research on women's experiences in planning vaginal breech birth (Homer et al. 2015) were also invited by email to complete the survey anonymously via SurveyMonkey ${ }^{\circledR}$.

All potential respondents were provided with clear information about the nature of the data being collected and the identity of the organisation holding the data where the research team was based. They were also advised of the purpose for which the data were going to be used and informed that all responses were anonymous. The survey took approximately 30 minutes to complete. A research team member checked social media pages regularly to respond to any further questions that may have arisen from potential respondents.

\section{Data Analysis}

Two members of the research team used inductive thematic analysis to analyse and code the data (Liamputtong 2005). Thematic analysis was used as it has been cited as a process that identifies patterns that uncover true meanings in the data (Betts, Dahlen \& Smith 2014; Boyatzis 1998; Grbich 2007).

The qualitative components of the survey were read and re-read by two members of the research team with the intention of gaining familiarity with the text. Following this process, initial identification of codes and potential themes occurred through colour coding of transcripts by hand. The accuracy of how to sort codes with similar content into sub-themes was confirmed in discussions between the two researchers.

Major themes were generated from the sub themes and then compared with the entire data set to confirm authenticity and to ensure the experience of the respondents were captured (Taylor, Kermode \& Roberts 2006). Where there was divergence of opinion the data was re-examined, themes revisited and refinements or changes were made (Dahlen \& Homer 2011). Themes have been generated using the women's exact words as they provided compelling examples of the responses included in the survey and were representative of the themes (Betts, Dahlen \& Smith 2014; Homer et al. 2015). A third and fourth 
researcher then critiqued these findings and themes, which allowed for further refinement of the results.

\section{$\underline{\text { Results }}$}

In total 204 women responded to the survey. Table 1 outlines the demographic characteristics of survey respondents. Most of the participants (44.3\%) were between 31-35 years of age and were from the United States of America or Australia. More than three-quarters of the women had tertiary education (76.3\%). Over one third of those who responded to the question relating to parity (62.9\%) had given birth more than once. Of the 164 who disclosed their mode of birth, 104 women had a VBB (63.4\%). 
Table 1 Women's demographic characteristics

\begin{tabular}{|c|c|c|}
\hline Country of origin & $\begin{array}{l}\text { Number } \\
(n=185)\end{array}$ & (\%) \\
\hline United States & 67 & $(36.2)$ \\
\hline Australia & 55 & $(29.7)$ \\
\hline United Kingdom & 22 & (11.9) \\
\hline Canada & 17 & (9.1) \\
\hline New Zealand & 14 & (7.5) \\
\hline South Africa & 3 & (1.6) \\
\hline Germany & 2 & (1.0) \\
\hline Other & 5 & (2.7) \\
\hline Age (years) & $\begin{array}{l}\text { Number } \\
(n=203)\end{array}$ & (\%) \\
\hline $18-25$ & 9 & (4.4) \\
\hline $26-30$ & 47 & $(23.2)$ \\
\hline $31-35$ & 90 & (44.3) \\
\hline $36-40$ & 38 & $(18.7)$ \\
\hline$>41$ & 19 & (9.4) \\
\hline $\begin{array}{l}\text { No. of } \\
\text { children }\end{array}$ & $\begin{array}{l}\text { Number } \\
(n=197)\end{array}$ & $(\%)$ \\
\hline 1 & 73 & $(37.1)$ \\
\hline 2 & 64 & (32.5) \\
\hline 3 & 28 & $(14.2)$ \\
\hline 4 & 19 & (9.6) \\
\hline
\end{tabular}




\begin{tabular}{lcc} 
Education & Number & (\%) \\
\hline High School & 31 & $(16.3)$ \\
University & 145 & $(76.3)$ \\
\hline Apprentice/Technical & 16 & $(8.4)$ \\
\hline Mode of birth for their & Number \\
breech presenting baby & $(\mathrm{n}=164)$ \\
\hline Vaginal & 104 & $(\%)$ \\
\hline Em. CS & 60 & $(63.4)$
\end{tabular}

Written responses to the open ended questions in the survey ranged widely from a few words to longer, more detailed answers. Seven themes were generated from these responses: Seeking the chance to try for a VBB; Encountering coercion and fear; Putting the birth before the baby?; Dealing with emotional wounds; Searching for information and support; Traveling across boundaries; Overcoming obstacles in the system.

These are presented below with quotes to illustrate the key concepts. Direct quotes are referenced by participant number (for example: Participant 1-P1) 


\section{Seeking the chance to try for a VBB}

Women expressed the desire to labour and give their bodies a chance to attempt to give birth to their babies vaginally. While there was disappointment that for some, a CS was required, there was satisfaction in knowing that they had tried their best. It seemed to be important for them to know they had done everything they could to maximise the chance of vaginal birth. Rather than seeing a CS as a failure, women instead felt it would be a failure to not explore the opportunity to give themselves a chance for vaginal birth, for example, one woman wrote:

"It didn't work as a vaginal birth which was disappointing as my first birth was natural and lovely, but I'm ok with it because I tried everything to turn it and deliver it. A c section was my last option but that is ok. Baby is here now and I have no regrets because at least I tried. I would have felt completely cheated if my only option had been a caesar and I would have felt like I had failed."(P 35)

Women regretted not having access to this care or feeling like they had a voice in order to express their wishes for birth of their baby. For those women who were not given the opportunity to try, the sense of loss was significant, for example:

"It was the most disempowering experience of my life." (P36)

While the experience of meeting their baby for the first time was an exciting and moving experience, women felt that the disempowerment they experienced had left a mark that was long lasting. Women seemed to want or need the chance to try for a vaginal birth and were regretful if this could not happen. 


\section{Encountering coercion and fear}

Respondents wanted to be able to make a choice for their birth option and when they expressed this desire, they felt further disempowered when they experienced 'scare tactics' and judgmental attitudes from care providers. Women felt this was a direct cause of the stress they experienced in the final weeks of their pregnancy. The presence of supportive partners and clinicians did not preclude them from experiencing negative sentiments and threats from other staff present who were not supportive of VBB. One woman wrote:

"I was not happy with the threats and bullying which continued into labour - in the complete absence of any medical problems whatsoever I should add, it was a textbook breech/vertex twin birth. [They said] 'You have to get on the bed for a VE (vaginal examination)-you don't have a choice, your babies are going to die, you are going to die, why did you come here if you don't want us to help you, your kids will be left without a mother....' " (P 23)

Lack of clinician engagement was also cited by women as an element of care that was unsupportive of their choices. Women who sought the opportunity to have informed discussions with their care provider and engage in shared decision-making did not feel they were given this opportunity. Instead, they were treated as an inconvenience, with their decision-making process for birth being treated as unimportant. One woman explained this:

"It was either: planned caesarean section or not. 'Have you made up your mind yet? I am busy, go outside and see me if I have a spare minute to let me know what you want. If you don't go for a planned caesarean section and you end up with an emergency caesarean section you are at the bottom of our list. That was the info I got. It was bullying, and giving me options as if I could choose between a cappuccino or an americano." (P 56) 
Women felt their views and wishes about the birth of their baby were not listened to and this caused a sense of isolation and vulnerability.

\section{Putting the birth before the baby?}

Pressure and judgement from family members also featured strongly during the decision-making process for women who responded to the survey. The resulting stress and anxiety had the potential to impact on the birth experience, for example:

"I feel like breech is a highly politicised area-and the weight of negativity is against you. People feel free to tell you that the thought of a breech baby was "their worst nightmare" during their pregnancy; people are quick to label the baby stubborn or difficult; you have to answer to everyone about why you are potentially risking the baby's life in order to deliver it naturally. I didn't feel supported from diagnosis of breech to day of birth. It was a very difficult time between myself and my partner and our families. The birth ended up being very, very difficult in terms of what was going on in my relationship and with family members." (P 18)

Accusations of women 'putting the birth before the baby' were also common. Women felt that society's view was that seeking a VBB was selfish. Women were driven to find support online, where social media connected them with other women who sought VBB. This was explained by this example:

"Friends and family were terrified and uninformed. I was told I was putting the safety of my baby at risk because of my own desires to have a natural birth. The reality is that I wanted a natural birth for the benefit of my baby! Most friends told me that I was being selfish and that it was way too dangerous." (P 18) 
Fielding negative views and judgements of others was a common theme from many of the respondents in this survey. While some were able to remain confident about their choices, other felt it had a profound impact and caused significant anxiety in the lead up to the birth of their baby.

\section{Dealing with emotional wounds}

Women spoke of experiencing stress and anxiety during the decision-making process for VBB.

Additionally, for some, the day of their baby's birth was recalled as a mostly negative experience, with the only positive aspects being a sense of satisfaction that they had fought as hard as they could to optimise the chance of VBB, for example:

"My baby's birth day was filled with stress, anger, fear and injustice. The only part that felt good was that I did my very best to advocate for myself." (P 63)

Women also discussed the longer term impacts of how this stress manifested itself and the effects it had on their immediate relationships. This was explained:

"It was a very difficult experience for my partner and I, who weren't 100\% reconciled on the decision I made to try and deliver. The effects of this continued after the birth, too. It's taken two years and another baby (head down, born naturally) to heal some of those emotional wounds." (P 18)

Women felt there was a lack of recognition of the potential for negative long term impacts when experiencing stressful negotiations around birth late in pregnancy. One woman identified as having developed significant mental health problems during the postnatal period that she linked directly to the challenges she experienced when making the decision to try for a VBB and negotiating her desired birth plan. She explained: 
"I had PND (postnatal depression) and honestly believe it started in pregnancy as a result of the stress and unhappiness I felt whilst fighting everyone to get the birth I wanted." (P 3)

These responses indicate there is potential for considerable psychological impact on those that felt it was a significant struggle to search for supportive care.

\section{Searching for information and support}

Women who were unable to access clinicians supportive of VBB found obtaining information to assist them in making an informed decision challenging. The lack of available counselling drove them to do their own research, which they feel had a profound impact on their birth choices and final outcome. One woman explained:

"My antenatal care was disjointed and challenging, was laughed at by Doctors and had no proper counselling, and was given no proper options other than an elective caesarean. I was never given any detailed statistics, all I was given was threats of dead babies if I didn't comply. It was very much a "pull" system for information. Had we not done our own research, we would've had a cesarean." (P 34)

It was difficult for women to feel like they had comprehensive information from clinicians to make an informed decision. As a result, women turned to the internet to seek information, both through websites and by sharing information with other women on social media. Approximately $50 \%$ of respondents used social media websites to connect with other women and seek information through those channels. Reading other women's birth stories was comforting and provided a sense of relief from the isolation they were experiencing, for example: 
"It [social media] was hugely helpful and motivating when making our decision. It was very useful to read birth stories and get good support online from breech moms across the globe." (P 18)

The internet was used as a tool for information sharing and helped women build confidence in their decision-making processes. For those who had the means to travel late in the pregnancy, it was also used to seek information on the location of clinicians skilled in VBB outside of their local area.

\section{$\underline{\text { Traveling across boundaries }}$}

It was common for women to change care providers later in pregnancy to access care providers that were supportive of VBB. Most women spoke of doing their own research to find these care providers after feeling unsupported by the care provider they had accessed for most of their pregnancy. For some, this meant travelling long distances to access this care. This woman said:

"There were zero providers in my area so I contacted a doctor interstate in - 8 hours north. He was both skilled, confident and relaxed so we traveled to his hospital. My water broke as we arrived and, 24 hours later, I had my beautiful breech baby, vaginally." (P 29)

Transferring facilities to access VBB was not always a positive experience. Women resented being forced to make choices to avoid personal conflicts and the need to feel grateful to clinicians for being 'saved' from intervention that was potentially unnecessary to begin with. One woman explained:

"I sometimes regret having transferred care and not sticking up for myself and demanding my rights in the public system. My husband was against anything that might involve conflict and that was a big part of my decision. If I'd had the support of somebody who was not scared to advocate for me, I may have made different choices. I would have preferred to work with the system rather than leave the system so I 
have regrets about that. I also really hate the fact that I am expected to be 'grateful' to the Obstetrician who 'saved me' from a caesarean that I didn't need." (P 55)

For the women in this survey, accessing supportive care was challenging and often required significant effort and anxiety to travel across service boundaries or state lines to access supportive care.

\section{Overcoming obstacles in the system}

The women who responded in this survey found themselves negotiating a system of care in conflict over VBB. Women who felt they had established support for VBB found that this was not always sufficient and that there were additional obstacles to overcome at a system wide level. They stated that their clinician's 'hands were tied' by system attitudes towards VBB that sought to prevent the option being available to women seeking it, for example:

"I was already being attended by a group of hospital midwives skilled in VBB, which I confirmed several times in the second half (of pregnancy). At 37 weeks they finally disclosed that although they were skilled and experienced, hospital policy did not allow for them to attend a primip VBB even with informed consent and informed refusal of a cesarean." (P 19)

Respondents expressed concern that the lack of system wide support for VBB was limiting the opportunity for supportive clinicians to observe VBB. They feared that the limited, or non-existent, chances for clinicians to develop skills would impact on the availability of choice for women seeking a VBB in the future. This was explained: 
"I feel it's a shame there is not more education and support for new doctors coming through. They can't support us mums of breechlings if they aren't supported themselves. I'm genuinely fearful that the option of breech vaginal births will die out as the skills are being lost as CS has become the norm." (P 11)

The women recognised the importance of clinician skill in maintaining the availability of VBB and recognised that lack of wider system support for VBB had a significant impact on opportunities for clinicians to gain and maintain these skills.

\section{Discussion}

This study sought the views of women from a number of countries about their expectations and experiences surrounding planned VBB . In summary, women found it challenging to find supportive care as many clinicians and health facilities they encountered were not supportive of this option for birth. Women were faced with negativity from both unsupportive clinicians and social circles about the option of VBB. Those who were unable to obtain information to support their decision-making for VBB turned to social media and the internet and used this forum as a means to find supportive clinical care, with some having to travel long distances to access this care.

\section{System centred care vs woman centred care}

Women seeking a VBB in this study found themselves negotiating a system where they no longer felt at the centre of the pregnancy and birth process. Clinician and facility concern over risks associated with VBB created a 'system centred' approach where health facilities were led by perceptions of risk around VBB. This resulted in women being denied the opportunity to explore their desired birth option.

Similar results were reported in a qualitative study of 22 women that explored their decision-making process for VBB (Homer et al. 2015). The women cited a lack of autonomy and control in their decisionmaking and attributed this to entrenched clinician and system views regarding the risks associated 
vaginal VBB. These views are difficult for health systems to shift. When faced with a woman seeking to explore this birth option, health systems seek to manage the woman by dictating her options to her rather than maintaining her as the focus of the pregnancy and birth process.

System attitudes to VBB may be a result of it being viewed as outside the parameters of normal birth, thereby requiring increased surveillance and risk management (Homer et al. 2015; Murphy 2010). The decline in clinicians skilled in VBB further reinforces the current perceptions of the need to medically manage breech presentation by engaging CS as default practice of the birth of a breech baby (Berhan \& Haileamlak 2016; Glezerman 2012). The preference for medicalisation and control of birth for perceived guarantee of safe outcomes directly opposes the woman-centred focus in favour of the technocratic approach whereby medical management of birth is seen as the superior option to vaginal birth (Coxon, Scamell \& Alaszewski 2012; Davis-Floyd 2001, 2003; Scamell 2014; Scamell \& Alaszewski 2012, 2016). Women seeking VBB may often pose a challenge to obstetric maternity care that is characterised by paternalistic authority and decision-making for the woman, rather than in collaboration with the woman (Cheyney, Everson \& Burcher 2014; Homer et al. 2015). These current norms are seen as an attempt to control power and preserve authority in obstetric care which relies on the ritualised medicalisation of birth. Women seeking VBB are a threat to this authority and challenge the ritualised behaviour of CS for management of the breech presenting baby. Ritualised medical norms have also been cited to inform social discourse, which, for VBB, may reinforce CS as the safest option for breech birth (Coxon, Sandall \& Fulop 2014; Coxon, Scamell \& Alaszewski 2012; Davis-Floyd 2003; Homer et al. 2015).

\section{The impact of anxiety and the need for support}

Pressure from the women's social circles, in addition to negative clinician views regarding VBB, created anxiety for many of the women in this study during their last weeks of pregnancy. Stress and anxiety during the antenatal period has been shown to increase the potential for childbirth interventions, emergency and elective CS, postnatal depression, post-traumatic stress disorder and depression (Buist 
et al. 2008; Donnellan-Fernandez 2011; Fisher, Hauck \& Fenwick 2006; Söderquist et al. 2009). Current evidence also suggests that maternal anxiety during the antenatal period can also have poor long term health implications not only for the mother but also for the baby postnatally (Ding et al. 2014; Hector, LeFevre \& Williamson 1989; Leigh \& Milgrom 2008).

Existing research on decision-making for breech birth suggests that women feel a sense of isolation in their decision-making for VBB (Guittier et al. 2011; Homer et al. 2015). Therefore healthcare providers should give close attention to anxiety in pregnant women and make all attempts address any concerns from the woman that may arise. For women with breech babies, the time from diagnosis of breech to birth can be intensely stressful, as evidenced by the women's stories in the findings of this study. It is important for clinicans to ensure women with a breech baby feel supported in the final weeks of their pregnancy to prevent anxiety from escalating.

\section{The challenge of shared decision-making for vaginal breech birth}

The women in this study reported feeling stress and anxiety because they were not able to access care that was supportive of VBB. The women who encountered resistance to VBB found the traditional process of provider-led decision-making failed to prioritise their medical, social and psychological factors that may have played a role in the decision to seek a VBB. This has previously been identified as an obstacle to shared decision-making between the care provider and the woman (Cox 2014). Those who felt they had maintained autonomy through shared decision-making with their treating clinicians reported feeling more positive about their experience, regardless of the eventual mode of birth. They spoke of preserving a sense of control and feeling a sense of satisfaction at having 'exhausted all the options' to try for VBB.

Shared decision-making can be seen as a midpoint between "paternalistic" and "informed choice" models of decision-making and is characterised by a patient and health care provider relationship where information is shared and management decisions are agreed upon (Elwyn, Edwards \& Kinnersley 
1999; Müller-Engelmann et al. 2011). Shared decision-making has been shown in the literature to have a number of benefits for women's decision-making in birth scenarios that may be considered challenging for clinicians (Cox 2014; Nieuwenhuijze et al. 2014; Shorten et al. 2004). It has also been cited as encouraging evidence-based practice and incorporation of women's values and preferences and it has also been suggested that it may reduce the likelihood of malpractice liability (Bryant et al. 2007; Cox 2014; Kaimal \& Kuppermann 2010). The importance of clinicians providing information to women to make informed choices has recently been emphasised by the Supreme Court of the UK in Montgomery v Lanarkshire Health Board (Powell, Walker \& Barrett 2015). The outcomes of this case emphasised the need for those receiving medical care to be made fully aware of risks and benefits of all options for care. In the context of breech birth, therefore, clinicians also have legal and professional duties to support the process of shared decision making by providing full and unbiased information to women diagnosed with a breech baby during pregnancy.

The challenge of incorporating shared decision-making for VBB may include a lack of system support for clinician training and upskilling to support VBB, thereby creating an entrenched bias in favour of CS as the preferred management option (Glezerman 2012; Lawson 2012). Challenging limited system and clinical support for VBB requires recognition of existing evidence on the safety of VBB and recognition of the need to provide unbiased information on VBB in an accessible manner as well as increasing access to clinicians skilled in supporting vaginal breech birth through structured and targeted education (Azria et al. 2009; Goffinet et al. 2006; Lawson 2012; Walker, Scamell \& Parker 2016).

By combining evidence-based practice and shared decision making, women's views will be valued and their preferences will be prioritised (Cox 2014). A useful model that may assist in supporting this process entails five steps of evidence based inquiry: 1) finding out what is important to the woman and her family 2) using the information from the clinical examination 3) seeking and assessing the evidence to inform decisions 4) talking it through 5) reflecting on outcomes, feelings and consequences (Page \& McCandlish 2006). 
Maternity services should also acknowledge that women are likely to continue to choose VBB as an option for birth and that shared decision making should be recommended in clinical guidelines that are developed for guidance on the management of breech presentation. This approach is supported in existing research (Homer et al. 2015; Kotaska 2007) as well as clinical guidelines for management of breech presentation from the UK and Canada (Kotaska et al. 2009; RCOG 2006). These documents contain clear statements about the need to respect a woman's decision and that information on risks and benefits for all option for birth should be provided. There is also some evidence emerging of specialist multidisciplinary teams to support planned vaginal breech births wherever possible, along with some other services who support formal referral processes and counselling of women prior to decision making for VBB (Borbolla Foster et al. 2014; Maier et al. 2011; Marko et al. 2015; Walker, Scamell \& Parker 2016). Increasing the existence of such services may raise the profile of VBB as a valid option and, given the influence medical discourse has on social discourse (Coxon, Sandall \& Fulop 2014; Coxon, Scamell \& Alaszewski 2012), may also impact on the acceptability of VBB in socio-cultural contexts as a normative practice.

One limitation of this survey is that it was provided in English only and excluded women who do not speak English and could access the internet and social media. The sample size was relatively small given the membership of each of the Facebook groups from the United States, United Kingdom and Australia had over 1,000 members in each group. Distribution of the survey was also limited to these social media sites, making it inaccessible to women who may not use social media. Survey responses were not identified or analysed by country. A large proportion of respondents were from the United States, where access to VBB is limited in many states and this may have influenced the results. Additionally, the differences in the provision of maternity care and the training and skill of clinicians may have also influenced the findings. However, this survey is the first of its kind to examine this issue. The views of this group of women and the results should be considered in obstetric and midwifery practice.

\section{Conclusion}


Women with a breech presentation diagnosed late in pregnancy may choose to explore the option of VBB. Limited system and clinical support for VBB can impede women's access to balanced information for decision-making and sourcing care that is supportive of VBB. This potentially increases maternal anxiety and, from a service provision perspective, diminishes woman-centred approaches to care. Recognition of existing evidence on the safety of VBB, as well as the presence of clinical guidelines that includes support for VBB, may assist in shared decision-making for VBB and promoting VBB as a legitimate option for birth that should be available to women for birth of their breech baby.

Disclosure Statement: The authors declare that they have no competing interests, financial interest or benefit arising from this research. 


\section{$\underline{\text { References }}$}

Azria, E., Schmitz, T., Bourgeois-Moine, A., Goffinet, F., Tsatsaris, V. \& Mahieu-Caputo, D. 2009, 'Peut-on concilier autonomie maternelle et responsabilité médicale dans les décisions de voies d'accouchement des fœtus en siège ? Rôle de l'information', Gynécologie Obstétrique \& Fertilité, vol. 37, no. 6, pp. 464-9.

Berhan, Y. \& Haileamlak, A. 2016, 'The risks of planned vaginal breech delivery versus planned caesarean section for term breech birth: a meta-analysis including observational studies', BJOG: An International Journal of Obstetrics \& Gynaecology, vol. 123, no. 1, pp. 49-57.

Betts, D., Dahlen, H.G. \& Smith, C.A. 2014, 'A search for hope and understanding: An analysis of threatened miscarriage internet forums', Midwifery, vol. 30, no. 6, pp. 650-6.

Borbolla Foster, A., Bagust, A., Bisits, A., Holland, M. \& Welsh, A. 2014, 'Lessons to be learnt in managing the breech presentation at term: An 11-year single-centre retrospective study', Australian and New Zealand Journal of Obstetrics and Gynaecology, vol. 54, no. 4, pp. 333-9.

Boyatzis, R.E. 1998, Transforming Qualitative Information: Thematic Analysis and Code Development, Sage Publications.

Bryant, J., Porter, M., Tracy, S.K. \& Sullivan, E.A. 2007, 'Caesarean birth: Consumption, safety, order, and good mothering', Social Science \& Medicine, vol. 65, no. 6, pp. 1192-201.

Buist, A.E., Austin, M.-P.V., Hayes, B.A., Speelman, C., Bilszta, J.L.C., Gemmill, A.W., Brooks, J., Ellwood, D. \& Milgrom, J. 2008, 'Postnatal mental health of women giving birth in Australia 2002-2004: findings from the beyondblue National Postnatal Depression Program', The Australian And New Zealand Journal Of Psychiatry, vol. 42, no. 1, pp. 66-73.

Catling, C., Petrovska, K., Watts, N., Bisits, A. \& Homer, C.S. 2016, 'Barriers and facilitators for vaginal breech births in Australia: Clinician's experiences', Women Birth, vol. 29, pp. 138-43.

Cheyney, M., Everson, C. \& Burcher, P. 2014, 'Homebirth Transfers in the United States: Narratives of Risk, Fear, and Mutual Accommodation', Qualitative Health Research, vol. 24, no. 4, pp. 443-56.

Cox, K.J. 2014, 'Counseling Women with a Previous Cesarean Birth: Toward a Shared Decision-Making Partnership', Journal of Midwifery \& Women's Health, vol. 59, no. 3, pp. 237-45.

Coxon, K., Sandall, J. \& Fulop, N.J. 2014, 'To what extent are women free to choose where to give birth? How discourses of risk, blame and responsibility influence birth place decisions', Health, Risk \& Society, vol. 16, no. 1, pp. 51-67.

Coxon, K., Scamell, M. \& Alaszewski, A. 2012, 'Risk, pregnancy and childbirth: What do we currently know and what do we need to know? An editorial', Health, Risk \& Society, vol. 14, no. 6, pp. 50310.

Dahlen, H.G. \& Homer, C.S.E. 2011, 'Motherbirth or childbirth'? A prospective analysis of vaginal birth after caesarean blogs', Midwifery, vol. 29, no. 2, pp. 167-73.

Davis-Floyd, R. 2001, 'The technocratic, humanistic, and holistic paradigms of childbirth', International Journal of Gynecology \& Obstetrics, vol. 75, Supplement 1, pp. S5-S23.

Davis-Floyd, R. 2003, Birth as an American rite of passage, University of California Press.

Ding, X.-X., Wu, Y.-L., Xu, S.-J., Zhu, R.-P., Jia, X.-M., Zhang, S.-F., Huang, K., Zhu, P., Hao, J.-H. \& Tao, F.-B. 2014, 'Maternal anxiety during pregnancy and adverse birth outcomes: A systematic review and meta-analysis of prospective cohort studies', Journal of Affective Disorders, vol. 159, pp. 103-10.

Donnellan-Fernandez, R. 2011, 'Having a baby in Australia: women's business, risky business, or big business?', Outskirts: feminisms along the edge, vol. 24.

Elwyn, G., Edwards, A. \& Kinnersley, P. 1999, 'Shared decision-making in primary care: the neglected second half of the consultation', Br J Gen Pract, vol. 49, no. 443, pp. 477-82.

Fisher, C., Hauck, Y. \& Fenwick, J. 2006, 'How social context impacts on women's fears of childbirth: A Western Australian example', Social Science \& Medicine, vol. 63, no. 1, pp. 64-75. 
Glezerman, M. 2006, 'Five years to the term breech trial: The rise and fall of a randomized controlled trial', American Journal of Obstetrics and Gynecology, vol. 194, no. 1, pp. 20-5.

Glezerman, M. 2012, 'Planned vaginal breech delivery: current status and the need to reconsider', Expert Review of Obstetrics \& Gynecology, vol. 7, no. 2, pp. 159-66.

Goffinet, F., Carayol, M., Foidart, J.M., Alexander, S., Uzan, S., Subtil, D. \& Bréart, G. 2006, 'Is planned vaginal delivery for breech presentation at term still an option? Results of an observational prospective survey in France and Belgium', American Journal of Obstetrics \& Gynecology, vol. 194, no. 4, pp. 1002-11.

Grbich, C. 2007, Qualitative Methods for Health Research., Sage Publications,, London.

Guittier, M.-J., Bonnet, J., Jarabo, G., Boulvain, M., Irion, O. \& Hudelson, P. 2011, 'Breech presentation and choice of mode of childbirth: A qualitative study of women's experiences', Midwifery, vol. 27, no. 6, pp. e208-e13.

Hannah, M.E., Hannah, W.J., Hewson, S.A., Hodnett, E.D., Saigal, S. \& Willan, A.R. 2000, 'Planned caesarean section versus planned vaginal birth for breech presentation at term: a randomised multicentre trial', The Lancet, vol. 356, no. 9239, pp. 1375-83.

Hector, M., LeFevre, M. \& Williamson, H.A., Jr. 1989, 'Association between life stress and serious perinatal complications', Journal of Family Practice, vol. 29, no. 5, 1989/11//, p. 489+.

Hogle, K., Kilburn, L., Hewson, S., Gafni, A., Wall, R. \& Hannah, M. 2003, 'Impact of the international term breech trial on clinical practice and concerns: a survey of centre collaborators', J Obstet Gynaecol Can, vol. 25, pp. 14-6.

Homer, C.S.E., Watts, N., Petrovska, K., Sjostedt, C. \& Bisits, A. 2015, 'Women's experiences of planning a vaginal breech birth in Australia', BMC Pregnancy and Childbirth, vol. 15, no. 1, p. 89.

Kaimal, A.J. \& Kuppermann, M. 2010, 'Understanding Risk, Patient and Provider Preferences, and Obstetrical Decision Making: Approach to Delivery After Cesarean', Seminars in Perinatology, vol. 34, no. 5, pp. 331-6.

Kotaska, A. 2007, 'IN THE LITERATURE:Combating Coercion: Breech Birth, Parturient Choice, and the Evolution of Evidence-Based Maternity Care', Birth, vol. 34, no. 2, pp. 176-80.

Kotaska, A., Menticoglou, S., Gagnon, R., Farine, D., Basso, M., Bos, H., Delisle, M.F., Grabowska, K., Hudon, L., Mundle, W., Murphy-Kaulbeck, L., Ouellet, A., Pressey, T. \& Roggensack, A. 2009, 'SOGC clinical practice guideline: Vaginal delivery of breech presentation: no. 226, June 2009', Int J Gynaecol Obstet, vol. 107, no. 2, pp. 169-76.

Lagan, B.M., Sinclair, M. \& Kernohan, W.G. 2011, 'What Is the Impact of the Internet on Decision-Making in Pregnancy? A Global Study', Birth, vol. 38, no. 4, pp. 336-45.

Lawson, G.W. 2012, 'The Term Breech Trial Ten Years On: Primum Non Nocere?', Birth, vol. 39, no. 1, pp. 3-9.

Leigh, B. \& Milgrom, J. 2008, 'Risk factors for antenatal depression, postnatal depression and parenting stress', BMC Psychiatry, vol. 8, no. 1, p. 24.

Liamputtong, P. 2005, Qualitative Research Methods, Oxford University Press, South Melbourne.

Maier, B., Georgoulopoulos, A., Zajc, M., Jaeger, T., Zuchna, C. \& Hasenoehrl, G. 2011, 'Fetal outcome for infants in breech by method of delivery: experiences with a stand-by service system of senior obstetricians and women's choices of mode of delivery', Journal of Perinatal Medicine, vol. 39, no. 4, pp. 385-90.

Marko, K.I., Lewis, L., Kapner, M.D., Clausen, M., Casillas, S. \& Pinger, W.A. 2015, 'Cesarean Delivery Prevention: The Vaginal Breech Initiative at the George Washington University Hospital [116]', Obstetrics \& Gynecology, vol. 125, p. 42S.

Müller-Engelmann, M., Keller, H., Donner-Banzhoff, N. \& Krones, T. 2011, 'Shared decision making in medicine: The influence of situational treatment factors', Patient Education and Counseling, vol. 82 , no. 2 , pp. 240-6.

Munro, S., Kornelsen, J. \& Hutton, E. 2009, 'Decision making in patient-initiated elective cesarean delivery: the influence of birth stories', J Midwifery Womens Health, vol. 54, no. 5, pp. 373-9. 
Murphy, M.A. 2010, 'Medicalization of birth: The social construction of Cesarean section: A qualitative analysis', Ph.D. thesis, University of Michigan, Ann Arbor.

Nieuwenhuijze, M.J., Korstjens, I., de Jonge, A., de Vries, R. \& Lagro-Janssen, A. 2014, 'On speaking terms: a Delphi study on shared decision-making in maternity care', BMC Pregnancy and Childbirth, vol. 14, p. 223.

Page, L.A. \& McCandlish, R. 2006, The New Midwifery: Science and Sensitivity in Practice, Elsevier/Churchill Livingstone.

Petrovska, K., Watts, N.P., Catling, C., Bisits, A. \& Homer, C.S.E. 2016, 'Supporting Women Planning a Vaginal Breech Birth: An International Survey', Birth, pp. n/a-n/a.

Phipps, H., Roberts, C.L., Nassar, N., Raynes-Greenow, C.H., Peat, B. \& Hutton, E.K. 2003, 'The management of breech pregnancies in Australia and New Zealand', Australian and New Zealand Journal of Obstetrics and Gynaecology, vol. 43, no. 4, pp. 294-7.

Powell, R., Walker, S. \& Barrett, A. 2015, 'Informed consent to breech birth in New Zealand', The New Zealand Medical Journal (Online), vol. 128, no. 1418, pp. 85-92.

RCOG 2006, The management of breech presentation.

Romano, A.M., Gerber, H. \& Andrews, D. 2010, 'Social Media, Power, and the Future of VBAC', Journal of Perinatal Education, vol. 19, no. 3, pp. 43-52.

Scamell, M. 2014, 'Childbirth Within the Risk Society', Sociology Compass, vol. 8, no. 7, pp. 917-28.

Scamell, M. \& Alaszewski, A. 2012, 'Fateful moments and the categorisation of risk: Midwifery practice and the ever-narrowing window of normality during childbirth', Health, Risk \& Society, vol. 14, no. 2, pp. 207-21.

Scamell, M. \& Alaszewski, A. 2016, 'Choice, Risk, and Moral Judgment: Using Discourse Analysis to Identify the Moral Component of Midwives' Discourses', in J. Crichton, C.N. Candlin \& A.S. Firkins (eds), Communicating Risk, Palgrave Macmillan UK, London, pp. 67-82.

Shorten, A., Chamberlain, M., Shorten, B. \& Kariminia, A. 2004, 'Making choices for childbirth: development and testing of a decision-aid for women who have experienced previous caesarean', Patient Education and Counseling, vol. 52, no. 3, pp. 307-13.

Söderquist, J., Wijma, B., Thorbert, G. \& Wijma, K. 2009, 'Risk factors in pregnancy for post-traumatic stress and depression after childbirth', BJOG: An International Journal Of Obstetrics And Gynaecology, vol. 116, no. 5, pp. 672-80.

Taylor, B., Kermode, S. \& Roberts, K.E. 2006, Research in Nursing and Health Care: Evidence for Practice, Thomson Learning Nelson (Cengage), Melbourne.

van Roosmalen, J. \& Meguid, T. 2014, 'The dilemma of vaginal breech delivery worldwide', The Lancet, vol. 383, no. 9932, pp. 1863-4.

Walker, S., Scamell, M. \& Parker, P. 2016, 'Standards for maternity care professionals attending planned upright breech births: A Delphi study', Midwifery, vol. 34, pp. 7-14. 